\title{
cDNA Cloning of Human Plasminogen Activator-Inhibitor from Endothelial Cells
}

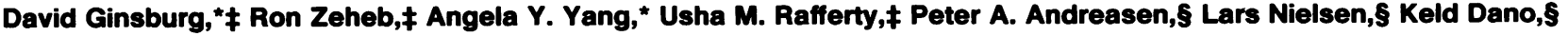 \\ Roger V. Lebo," and Thomas D. Gelehrterł \\ ${ }^{*}$ Howard Hughes Medical Institute, $\ddagger$ Departments of Internal Medicine and Human Genetics, University of Michigan Medical School, \\ Ann Arbor, Michigan 48109; §Finsen Institute, Copenhagen, Denmark; and "Howard Hughes Medical Institute, \\ University of California, San Francisco, California 94143.
}

\begin{abstract}
Full-length cDNA for plasminogen activator inhibitor (PAI-1) was isolated from a human umbilical vein endothelial cell (HUVEC) lambda gt11 cDNA library. Three overlapping clones were identified by immunologic screening of $10^{6}$ recombinant phage using a rabbit anti-human fibrosarcoma PAI-1 antiserum. The fusion proteins encoded by these three clones also react strongly with a monoclonal mouse anti-human fibrosarcoma PAI-1 antibody. By nucleotide sequence analysis, PAI-1 cDNA encodes a protein containing $\mathbf{4 0 2}$ amino acids with a predicted, nonglycosylated molecular mass of $\mathbf{4 5} \mathrm{kD}$. Identity of this material as authentic PAI-1 was confirmed by the presence of high level homology with the primary amino acid sequence of an internal peptide prepared from purified rat hepatoma PAI-1. The predicted amino acid sequence also reveals extensive homology with other members of the serine protease inhibitor gene family. Cultured HUVECs contain two PAI-1 mRNA species, both encoded by a single gene, differing by $1 \mathrm{~kb}$ in the $3^{\prime}$ untranslated region. The PAI-1 gene is located on human chromosome 7.
\end{abstract}

\section{Introduction}

Fibrinolysis is regulated, in part, by a balance between plasminogen activators (tissue plasminogen activator [tPA $]^{1}$ and urokinase PA [uPA]) and specific, rapidly acting inhibitors, plasminogen activator-inhibitors (PAIs) (1). Two major types of fast-acting PAI have been distinguished on the basis of biochemical and immunological properties, and designated PAI-1 and PAI-2. ${ }^{2}$ PAI-1 is a $50-54-\mathrm{kD}$, acid-stable glycoprotein found in plasma, platelets, endothelial cells, hepatoma cells, and fibrosarcoma cells (2-9). Vascular endothelial cells may represent the major site of synthesis for plasma PAI-1 $(1,3,5)$. In human umbilical vein endothelial cells (HUVECs), PAI-1 activity is induced by thrombin, endotoxin, and interleukin-1 (10-12) and

Address reprint requests to Dr. Ginsburg, Howard Hughes Medical Institute, Medical Science Research Building 1, Room 4520, University of Michigan Medical School, Ann Arbor, Michigan 48109.

Received for publication 14 August 1986.

1. Abbreviations used in this paper: Ab, antibody; HUVEC, human umbilical vein endothelial cells; PAGE, polyacrylamide gel electrophoresis; PAI, plasminogen activator-inhibitor, SERPIN, serine protease inhibitors; tPA, tissue plasminogen activator; uPA, urokinase PA.

2. Nomenclature recommended by the subcommittee on fibrinolysis of the International Committee on Thrombosis and Hemostasis, June 8, 1986.

J. Clin. Invest.

(C) The American Society for Clinical Investigation, Inc. $0021-9738 / 86 / 12 / 1673 / 08 \$ \$ 1.00$

Volume 78, December 1986, 1673-1680 decreased by protein C (13). PAI-1 has been shown to be induced by glucocorticoids in hepatoma and fibrosarcoma cells (14-16). Recently, abnormal plasma levels of PAI-1 have been associated with thromboembolic disease in humans (17-19). PAI-2 is a 60$\mathrm{kD}$ (glycosylated) or $47-\mathrm{kD}$ (nonglycosylated), acid-labile protein found primarily in placenta and monocyte macrophages (20, 21). We report here the isolation and characterization of fulllength cDNA sequences for human PAI-1.

\section{Methods}

Materials. The preparation of rabbit polyclonal anti-human fibrosarcoma (HT1080 cell line) PAI-1 IgG (8) and mouse monoclonal anti-human PAI-1 IgG ( $\left.\mathrm{IA}_{5} \mathrm{E}_{2}\right)(22)$, has been described previously. Antifibronectin antibody, affinity-purified, peroxidase-tagged, goat anti-rabbit IgG, and peroxidase-tagged, goat anti-mouse Igs were purchased from Cooper Biomedical (Malvern, PA). Restriction enzymes and T4 DNA ligase were purchased from New England Biolabs (Beverly, MA), or International Biotechnologies, Inc. (New Haven, CT), and reaction conditions were those recommended by the manufacturer. Nitrocellulose membranes (BA85) were purchased from Schleicher \& Schuell (Keane, NH). Oligonucleotide primers for construction of sequencing deletions (23) were purchased from International Biotechnologies, Inc. Radioisotopes and DNA sequencing reagents were purchased from Amersham Corp. (Arlington Heights, IL). Bluescribe transcription vector and T7 and T3 RNA polymerases were purchased from Stratagene (San Diego, CA). Guanylyltransferase was purchased from Bethesda Research Laboratories (Gaithersburg, MD). The in vitro translation kit was purchased from Promega Biotec (Madison, WI). Staphylococcus aureus protein A was obtained from Zymed Laboratories, Inc. (San Francisco, CA). All other reagents were of the best grade commercially available.

Immunoscreening of $c D N A$ library. The construction of the HUVEC lambda gt11 cDNA library used in these studies has been previously reported $(24,25)$. Immunoscreening of recombinant phage was performed by the method of Young and Davis (26) except that preincubation and antibody treatment of filters was performed in BLOTTO (10 mM Tris, $140 \mathrm{mM} \mathrm{NaCl}$, and 5\% Carnation nonfat powdered milk [pH 7.5]) (27). To remove any background anti-Escherichia coli antibody activity, antiPAI-1 antibody was diluted in BLOTTO and absorbed against nitrocellulose filters that had been presoaked with a lysate prepared from $E$. coli infected with wild type lambda gt11 (26). Isopropyl thio-beta-D-galactopyranoside-induced phage plaques were transferred to nitrocellulose filters $(24,26)$ and incubated for $3 \mathrm{~h}$ at room temperature in BLOTTOcontaining anti-PAI- 1 antibody (at a final dilution of $1: 100$ for polyclonal antibody [Ab] and 1:20 for monoclonal $\mathrm{Ab}$ ). Filters were washed three times in TBS (10 mM Tris and $140 \mathrm{mM} \mathrm{NaCl}$ [pH 7.5]), incubated for one hour at room temperature in BLOTTO containing a 1:500 or 1:200 dilution of peroxidase-conjugated second antibody, re-washed three times in TBS, and developed by immersion in substrate solution (10 mM Tris [pH 7.4] containing $20 \%$ methanol vol/vol, $0.06 \%$ 4-chloro-1-naphthol wt/vol, and $0.03 \% \mathrm{H}_{2} \mathrm{O}_{2} \mathrm{vol} / \mathrm{vol}$ ) (28). Positive clones were plaque purified through one to two additional rescreening steps, subcloned into pUC13 and analyzed by restriction enzyme digestion using standard methods (29).

Northern and Southern blot analysis. cDNA fragments were radiolabeled with $\left.{ }^{32} \mathrm{P}\right] \mathrm{dCTP}$ by random priming (30). Preparation of RNA 
and DNA, and Northern and Southern blot analyses were performed, as previously described $(24,29)$.

DNA sequence analysis. Full-length cDNA clones PAIB4 and PAIB6 were sequenced in $\mathrm{M} 13 \mathrm{mp} 18$ or $\mathrm{M} 13 \mathrm{mp} 19$ by constructing nested deletions using the method of Dale et al. (23). Sequence analysis for these and other clones (also subcloned into M13mp10, M13mp18, or M13mp19) was performed by the method of Sanger (31, 32). Sequence analysis was performed with the IBI-Pustell software package (International Biotechnologies, Inc.) (33), except for homology calculations, which used DNASTAR (Madison, WI) software using the Needleman-Wunsch algorithm (34).

Fusion protein and in vitro translation studies. Beta galactosidasePAI-1 fusion protein from antibody positive clones was prepared as previously described $(24,26)$ and analyzed by SDS-polyacrylamide gel electrophoresis (PAGE) and Western blotting using standard methods (35). RNA was transcribed in vitro from full-length CDNA clones PAIB4 and PAIB6 (subcloned into the transcription vector Bluescribe) using T7 and T3 RNA polymerase, and the RNA capped with guanylyltransferase using the conditions recommended by the manufacturers. This material was used in an in vitro translation assay, radiolabeled by incorporation of $\left[{ }^{35} \mathrm{~S}\right]$ methionine. Translated protein was immunoprecipitated using the purified IgG fraction of rabbit polyclonal anti-human fibrosarcoma PAI-1. $4.7 \mu \mathrm{g}$ of IgG was added to $70 \mu \mathrm{l}$ of translation mix and allowed to incubate for $30 \mathrm{~min}$ at room temperature and $2 \mathrm{~h}$ at $4^{\circ} \mathrm{C}$. IgG was recovered using insoluble $S$. aureus protein $\mathrm{A}$, the bound proteins released into SDS-PAGE sample buffer by heating $\left(100^{\circ} \mathrm{C}\right.$ for $\left.2 \mathrm{~min}\right)$, and then examined by SDS-PAGE and autoradiography.

Purification and amino acid sequence analysis of rat PAI-1. HTC rat hepatoma cell PAI-1 was purified by immunoaffinity chromatography from serum-free medium conditioned by cells incubated in the presence of $10^{-7} \mathrm{M}$ dexamethasone (Rafferty, U., R. Zeheb, P. Andreasen, and T. Gelehrter, manuscript in preparation). The functional integrity of the purified PAI-1 was confirmed using a coupled esterolytic assay $(9,11)$, and reverse fibrin autography (2). Peptide fragments were generated by treatment with cyanogen bromide, according to the method of Koide and Ikenake (36). One such fragment was purified by reverse-phase high pressure liquid chromatography and subjected to primary amino acid sequence determination (performed at the University of Michigan Protein Sequencing Facility [37]).

Chromosomal localization. Chromosome suspensions were prepared from a lymphocyte cell line in Tris-spermine buffer and stained with the 4'-6-bis(2'-imidazdinyl-4H,5H)-2-phenylindole-chromomycin A3 stain pair (38). 30,000 chromosomes of each type were sorted directly onto a single spot of a nitrocellulose filter paper using a Becton-Dickinson (Mountainview, CA) FACS IV sorter with a triple laser optical bench (39). The filter-bound chromosomal DNA was denatured, neutralized, prehybridized, and hybridized in $10 \%$ dextran sulfate $(38)$ for $18 \mathrm{~h}$ to random-primer-labeled PAIB6 insert (30). After washing to remove excess probe, the gene-specific signal was detected by autoradiography (38).

\section{Results}

Expression cloning of PAI-1 cDNA. One million recombinant clones from a lambda gt 11 cDNA library constructed from HUVEC mRNA were screened using a polyclonal rabbit anti-human PAI-1 antiserum. Six positive clones were initially identified. Three of these clones (PAI9, PAI17, and PAI20) were also positive when screened with a mouse anti-human monoclonal PAI1 antibody, and these same three clones also contained overlapping cDNA sequence as determined by cross hybridization with radiolabeled insert. Clone PAI19 encoded a fusion protein that also reacted with anti-fibronectin antibody and was probably due to background anti-fibronectin activity in our anti-PAI-1 antibody. Clones PAI7 and PAI18 cross-hybridized with each other but on Northern blot analysis of HUVEC mRNA recognized a single 1-kb mRNA species (data not shown), too small to encode human PAI-1, and thus were not examined further. Lysogens of phage clones PAI9, PAI17, and PAI20 were prepared in $E$. coli host $\mathrm{Y}-1089$, and fusion protein synthesis induced with isopropyl thio-beta-D-galactopyranoside. Fig. 1 shows SDSPAGE analysis of bacterial lysate prepared from one of these cultures. The wild type beta-galactosidase is replaced by a larger fusion protein. Western blot analyses using both the polyclonal and monoclonal anti-PAI-1 antibodies show immunoreactivity only with the fusion protein (Fig. 1).

The insert from clone PAI17 was radiolabeled and used as a probe to rescreen the cDNA library. Positive clones were identified with an abundance of $\sim 1: 1000.20$ new phage clones were isolated, most containing large inserts falling into two size classes of $\sim 3$ and $2 \mathrm{~kb}$, respectively. Fig. 2 shows a restriction map constructed from two such clones (PAIB4-[3 kb], PAIB6-[2 kb]). Positions for the original antibody positive clones are also indicated.

Characterization of PAI-1 CDNA. Radiolabeled insert from clone PAI17 was used in Northern blot analysis of mRNA from HUVECs, and the results are shown in Fig. $3 A$ (lane 1 ). Two mRNA species, $\sim 3$ and $2 \mathrm{~kb}$, are detected, with roughly equal intensity. Southern blot analysis (Fig. 3 B) also using PAI17 insert, detects a single band consistent with a single gene product. Fig. $3 A$ (lanes 2 and 3 ) shows the results of a Northern blot analysis using PstI/Rsal fragments A and B, respectively (see Fig. 2) as probe. Fragment A detects only the larger message, whereas fragment $B$ detects both species. This demonstrates that the 3- and 2-kb mRNA species differ only by an additional 1 $\mathrm{kb}$ of sequence at one end of the larger message.

RNA produced in vitro from clones PAIB4 and PAIB6, representative of the 3- and 2-kb mRNA species respectively, were used as template in an in vitro translation system. Fig. 4 shows the results of this experiment with PAIB4 as template. Identical results were obtained with PAIB6 (not shown). Both RNA species direct the synthesis of a 40-45-kD protein, which is immunoprecipitated by anti-PAI- 1 antibody.

Nucleotide sequence analysis. The complete sequence of clone PAIB4 was determined (confirmed by analysis of both strands), as well as partial sequence for PAI17, PAI9, PAI20, PAIB6, and several additional clones. Fig. $5 A$ shows the complete sequence. The first ATG codon appears 69 nucleotides from the $5^{\prime}$ end of the sequence and is followed by a 1,206-nucleotidelong open reading frame. The first 23 amino acids constitute a typical hydrophobic leader peptide. Fig. $5 B$ shows a hydrophobicity plot derived from the predicted amino acid sequence. There are three potential $\mathrm{N}$-glycosylation acceptor sites indicated in Fig. $5 A(40)$.

Amino acid residues $376-390$ show identity at 10 positions to a small region of primary peptide sequence obtained from purified rat PAI-1, including a segment of perfect homology for $8 / 8$ residues (Fig. $5 \mathrm{~A}$ ). Comparison of the predicted amino acid sequence with that of other reported serine protease inhibitors shows a high degree of homology between PAI-1 and other members of the serine protease inhibitor gene family (Table I).

Chromosomal localization. The PAI-1 gene was mapped by hybridization analysis of mitotic human chromosome suspensions sorted directly onto nitrocellulose filters. In two complete filter panels sorted from two different cell lines, GM 130 and GM 131, gene-specific hybridization was seen only to the spot containing chromosome 7 DNA. Fig. 6 shows the results with the GM130 filter panel. 


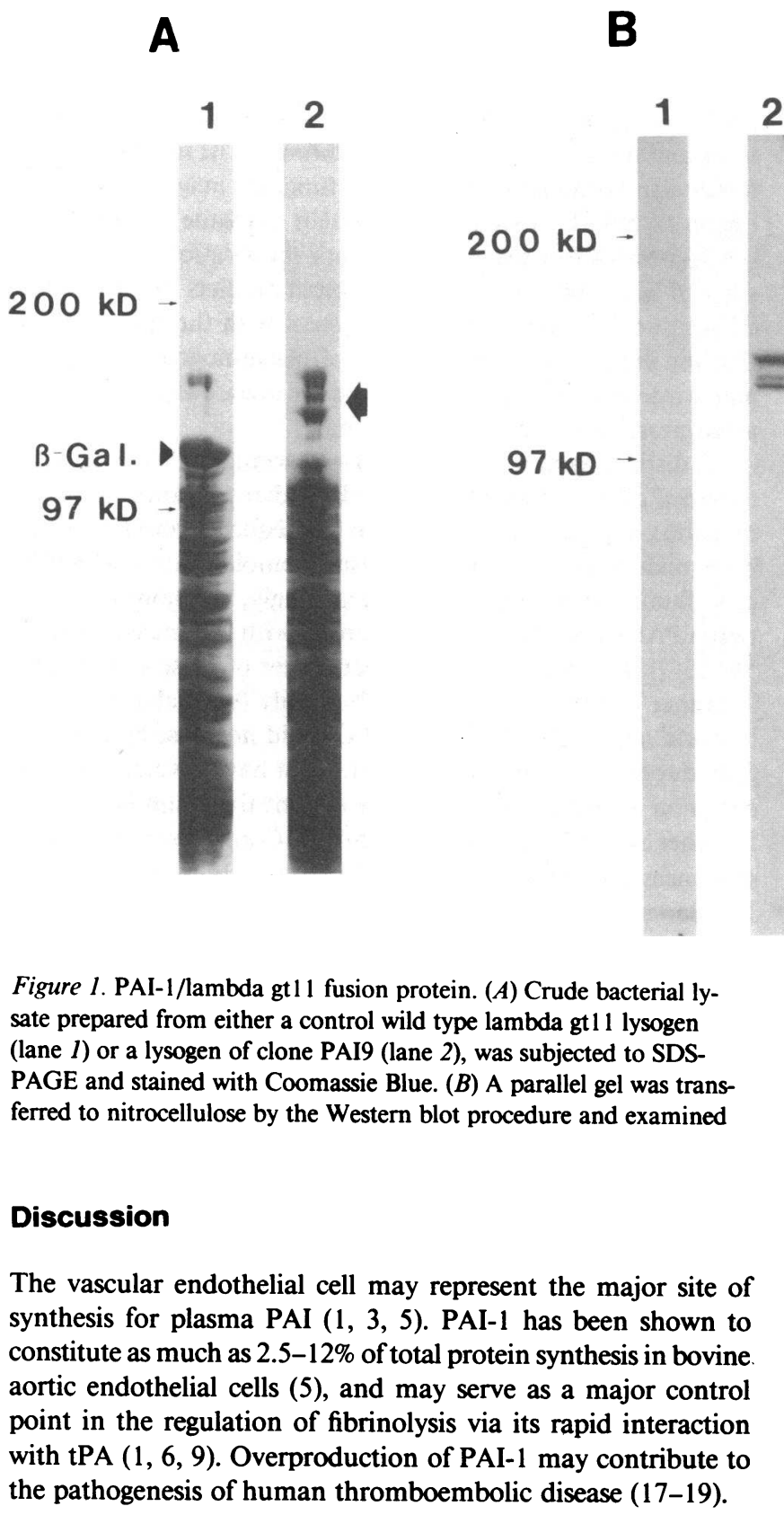

C

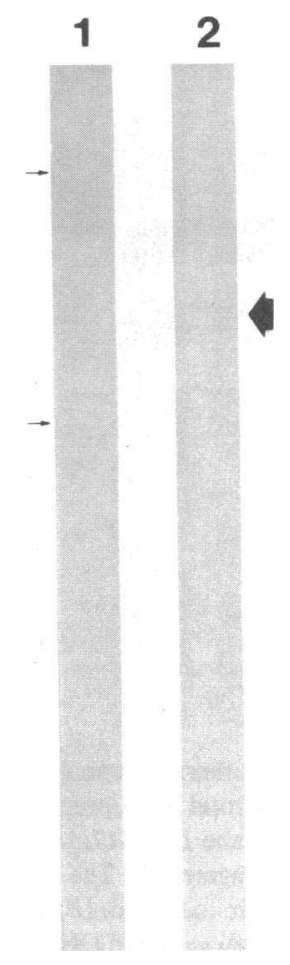

with polyclonal anti-PAI-1 antibody. The smaller bands are due to proteolytic degradation. $(C)$ A duplicate Western blot was stained with monoclonal anti-PAI-1 antibody $\mathrm{IA}_{5} \mathrm{E}_{2}$. Molecular mass standards are myosin, $200 \mathrm{kD}$; beta-galactosidase, $116 \mathrm{kD}$; phosphorylase $\mathrm{B}, 97 \mathrm{kD}$. Large arrows, the position of the fusion protein.

tPA and UPA are both serine proteases that share a number of structural features with other members of this closely related gene family including plasminogen, prothrombin, Factor IX, Factor X, protein C, and a number of other proteolytic enzymes (41). Therefore, it is not surprising that a specific inhibitor of plasminogen activators, PAI-1, also shares extensive homology with other serine protease inhibitors (SERPINS) $(42,43)$, as our sequence analysis demonstrates (Table I).

The first 150 amino acids at the $\mathrm{N}$-terminus of PAI- 1 show
0

$1 \mathrm{~kb}$
2 kb
$3 \mathrm{~kb}$

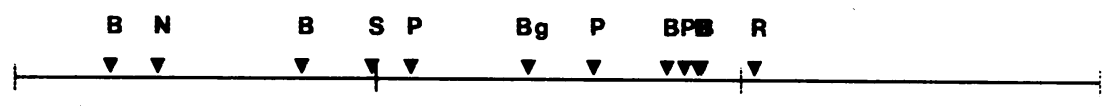

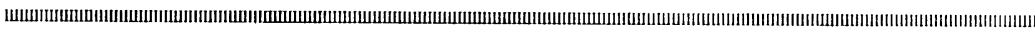
PAIB6

$$
\text { P-B }
$$

шA120

PAl17
Figure 2. PAI-1 restriction map. Location of restriction sites is indicated by the arrow heads. B, Bal I; Bg, Bgl II; N, Nco I; P, Pst I;

PAIB4 R, Rsa I, S, Sal I. All sites for these enzymes are shown except Rsa I for which only one of four sites is indicated. The relative positions of clones PAIB4, PAIB6, PAI20, PAI17, and PAI9 are shown. P-B, hybridization probe fragment B. P-A, hybridization probe fragment $\mathrm{A}$ (see text and Fig. $3 \mathrm{~A}$ ). The figure is drawn from 5 ' to $3^{\prime}$ (left to right) with respect to the coding sequence. 
A

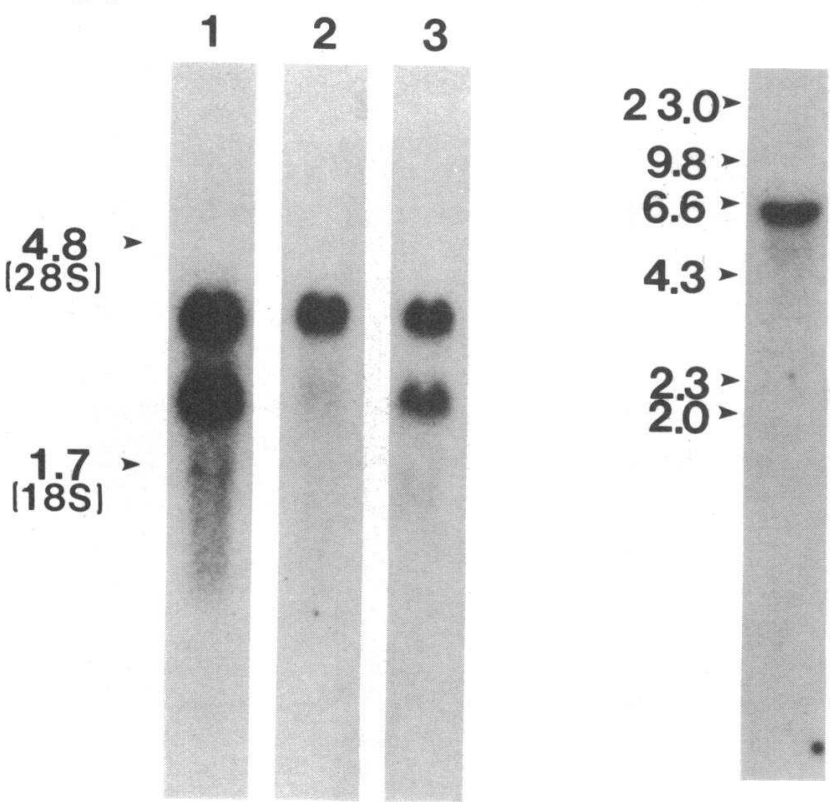

Figure 3. Northern and Southern blot analysis. $(A)$ Northern blot analysis was performed on total RNA prepared from cultured HUVECs. Probes used were: Lane 1, PAI17; lane 2, the 3' Rsa I fragment A; lane 3, the Rsa I/Pst I fragment B. The relative positions of ribosomal RNA size markers are indicated. $(B)$ Southern blot analysis of Eco RI digested, total human genomic DNA was performed with radiolabeled PAII 7 as a probe. The positions of DNA size markers are indicated. little homology to other SERPINs. Many of the other SERPIN family members also contain nonhomologous amino terminal extensions, some of which confer an activity related to their specific function. For example, the first $\mathrm{N}$-terminal 49 amino acids of angiotensinogen contain the angiotensin I and II peptides, and the first 25 residues of antithrombin III may contribute to heparin binding (43). A specific function may exist for this region of PAI-1 as well. By alignment with the sequences of other known serine protease inhibitors, the location of the active site can be deduced (43). Our alignment predicts Arg369 as the P1 residue. This alignment is consistent with the specificity of tPA for the Arg560-Val561 bond of plasminogen (44). Alternative interpretations are possible and the precise alignment must await more specific biochemical studies.

A distinct form of PAI is found in placenta. R. Ye et al. have obtained cDNA clones for PAI-2 (E. Sadler, personal communication), and comparison between this sequence and PAI-1 has been made. PAI-2 also shows extensive homology to the SERPIN gene family, including PAI-1. Surprisingly, the homology between PAI-1 and PAI-2 (29.6\% identity with optimized score of 554 [34]) is no higher than between either of these species and the other members of the SERPIN family (see Table I). Thus, it would appear that PAI-1 and PAI-2 did not arise by a recent gene duplication event, and in fact, must have diverged from a common ancestral gene at a more distant time, similar to that for other SERPIN gene family members. Comparison of the two sequences does reveal one region of striking homology at PAI1 amino acid residues 159-202 where 31 of 44 amino acids are identical to PAI-2. There is marked homology in this region at the DNA level as well (67\%). This area corresponds to a highly
A

\section{$\begin{array}{llll}1 & 2 & 3 & 4\end{array}$}

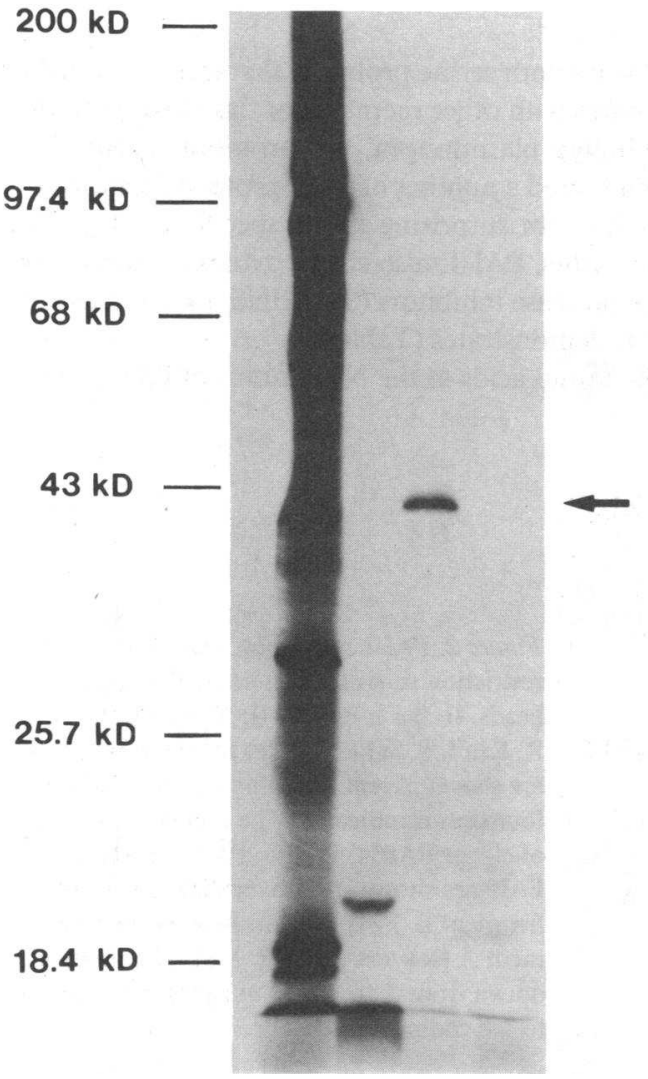

B

\section{$\begin{array}{llll}1 & 2 & 3 & 4\end{array}$}

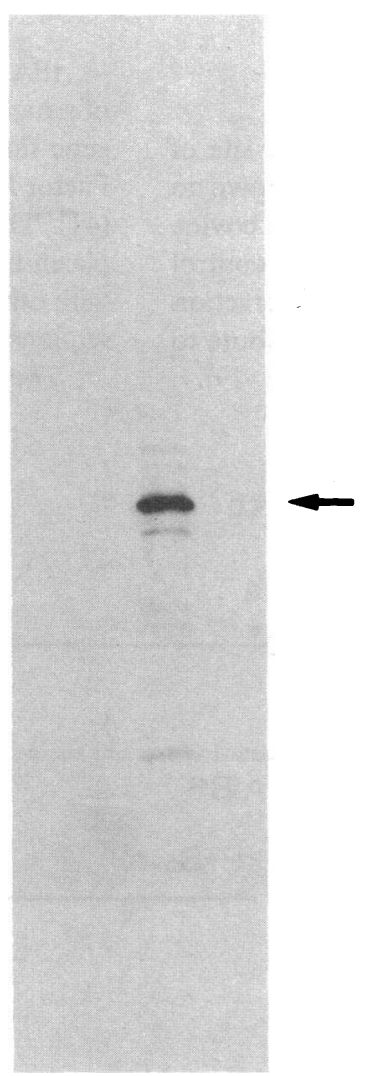

Figure 4. In vitro translation of PAIB4 RNA. RNA transcribed from clone PAIB4 was translated in vitro using a reticulocyte lysate system in the presence of $\left[{ }^{35} \mathrm{~S}\right]$ methionine. Panel $A$, total radiolabeled protein after SDS-PAGE and autoradiography. Panel $B$, the proteins immunoprecipitated with anti-PAI-1 antibody. Lane 1 , control translation using Brome mosaic virus mRNA as template; lane 2, translation using the anti-sense strand of PAIB4 as template; lane 3, translation using the coding strand of PAIB4 as template; lane 4, control translation with no RNA added. 


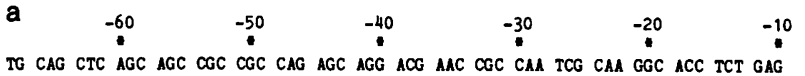

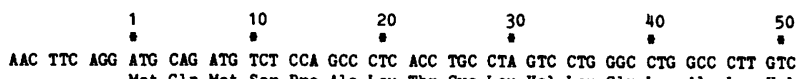
Met Gin Met Ser pro Ala Leu thr cys Leu Val Leu Gly Leu Ala Leu val 17

$\begin{array}{llllll}60 & 70 & 80 & 90 & 100 & 110\end{array}$

TIT GGT GAA GGG TCT GCT GTG CAC CAT CCC CCA TCC TAC GTG GCC CAC CTG GCC TCA GAC Phe Gly Glu Gly Ser Ala val His His Pro Pro Ser Tyr val ala his Leu Ala Ser Asp 37

$120 \quad 130 \quad 150 \quad 150 \quad 170$

TTC GGG GTG AGG GTG TTT CAG CAG GTG GCG CAG GCC TCC AAG GAC CGC AAC GTG GTT TTC Phe Gly val Arg val phe Gln Gin val ala Gin Ala Ser Lys Asp Arg Asn Val Val phe 57

$180 \quad 290 \quad 200 \quad 210 \quad 220 \quad 230$

TCA CCC TAT GGG GTG GCC TCG GTG TTG GCC ATG CTC CAG CTG ACA ACA GGA GGA GaA ACC

Ser Pro tyr Gly val ala ser val Leu Ala Met Leu Gin Leu Thr Thr Gly Gly Glu Thr 77

$240 \quad 250 \quad 260 \quad 270 \quad 280 \quad 290$

CAG CAG CAG ATT CAA GCA GCT ATG GGA TTC AAG ATT GAT GAC AAG GGC ATG GCC CCC GCC

Gin Gin Gin Ile Gin Ala Ala Met Gly phe Lys Ile Asp Asp Lys Gly Met Ala Pro 11 a 97

$300 \quad 310 \quad 320 \quad 330 \quad 340 \quad 350$

CTC CGG CAT CTG TAC AAG GAG CTC ATG GGG CCA TGG AAC AAG GAT GAG ATC AGC ACC ACA

Leu Arg His Leu Tyr Lys Glu Leu Met Gly Pro Trp Asn Lys Asp Glu Ile Ser Thr Thr 117

$\begin{array}{llllll}360 & 370 & 380 & 390 & 400 & 410 \\ \text { ATC TTC GTC CAG CGG GAT CTG AMG CTG GTC CAG GGC TTC ATC CCC CAC TTC TTC }\end{array}$

GAC GCG ATC TTC GTC CAG CGG GAT CTG AAG CTG GTC CAG GGC TTC ATC CCC CAC TTC TTC
Asp Ala Ile Phe Val Gla Arg Asp Leu Lys Leu Val Gln Gly Phe Met Pro H1s Phe Phe 137

$420 \quad 430 \quad 440 \quad 450 \quad 460 \quad 470$

AGG CTG TTC CGG AGC ACG GTC AAG CAM GTG GAC TTT TCA GaG GTG GaG AGA GCC AGA TTC

Arg Leu phe Arg Ser Thr val Lys Gin Val Asp phe Ser Glu Val Glu Arg Ala Arg phe 157

$480 \quad 490 \quad 500 \quad 510 \quad 520 \quad 530$

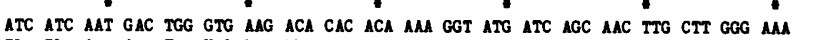

Ile Ile Asn Asp Trp val Lys Thr His Thr Lys Gly Met Ile Ser Asn Leu Leu Gly Lys 177

$$
540 \quad 550 \quad 560 \quad 570 \quad 580 \quad 590
$$

GGA GCC GTG GAC CAG CTG ACA CGG CTG GTO CTG GTG AAT GCC CTC TAC TTC AAC GGC CAG G1y Ala Val Asp G1n Leu Thr Arg Leu Val Leu val Asn A1a Leu Tyr phe Asn Gly Gln 197

$600 \quad 610 \quad 620 \quad 630 \quad 640 \quad 650$ TGG AAG ACT CCC TRC CCC GAC TCC AGC ACC CAC CGC CGC CTC TTC CAC AMA TCA GAC GGC
TrD Lys Thr Pro Phe Pro Asp Ser Ser Thr His Arg Arg Leu Phe His Lys Ser Asp Gly 217 $\begin{array}{lllll}660 & 670 & 680 & 690 & 700\end{array}$ AGC ACT GTC TCT GTG CCC ATC ATG GCT CAG ACC MAC AAG TTC MAC TAT ACT GAG TTC ACC Ser thr val Ser val Pro Met Met Mla Gin Thr Asn Lys phe Asn Tyr Thr Glu phe Thr 237
720
730
$740 \quad 750$
$760 \quad 770$

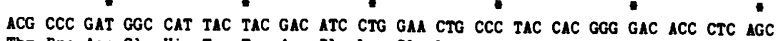
Thr Pro Asp Gly His Tyr Tyr Asp Ile Leu G1u Leu Pro Tyr His G1y Asp Thr Leu Ser 257
780
790
$800 \quad 810 \quad 820 \quad 830$

ATG TTC ATT GCT GCC CCT TAT GAS AM GAG GTC CCT CTC TCT GCC CTC ACC MC ATT CTO Met Phe Ile Ala Ala pro Tyr Glu Lys Glu Val pro Leu Ser Ma Leu Thr Asn IIJ Leu 277

$\begin{array}{lccccc}840 & 850 & 860 & 870 & 880 & 890 \\ \text { CAG CTC ATC AGC CAC TGG AMA GGC ACC ATG ACC AGG CTG CCC CGC CTC CTG GTT }\end{array}$

AGT GCC CAC CTC ATC AGC CAC TGG AM GGC AAC ATC ACC AGG CTG CCC CGC CTC CTC GTT
Ser Ala Gln Leu Ile Ser His Trp Lys Gly Agn Het Thr Arg Leu Pro Arg Leu Leu Val 297

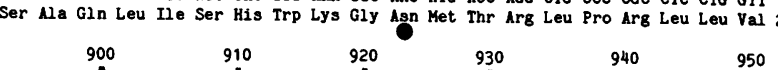

CTG CCC Ma TTC TCC CTG GaG ACT GAN GTC GAC CTC AGG AaG CCC CTA GAG MAC CTG GGA

Leu Pro lys phe Ser Leu Glu Thr Glu val Asp Leu Arg Lys Pro Leu Glu Asn Leu Gly 317

$$
960 \quad 970 \quad 980 \quad 990 \quad 1000 \quad 1010
$$

ATG ACC GAC ATG TTC AGA CAG TIT CAG GCT GAC TTC ACG AGT CTT TCA GAC CMA GAG CCT

Figure 5. (a) Full-length PAI-1 cDNA sequence. The complete cDNA sequence is shown with nucleotides numbered from the putative initiation codon. Amino acid residue numbers, beginning with the initiator methionine, are indicated at the right. The proposed leader peptide cleavage site is indicated by the arrow after amino acid 23 . Three potential N-glycosylation sites are indicated by circles. Alignment of primary amino acid sequence obtained from a small internal peptide of purified rat PAI-1 with amino acid residues $376-390$ is outlined in a box. Identical residues are denoted with an asterisk. The termination

hydrophobic portion of the molecule that immediately precedes the hydrophilic domain recognized by the monoclonal $\mathrm{Ab} \mathrm{IA}_{5} \mathrm{E}_{2}$ (Fig. $5 B$ ). This may represent a region of unique function shared by these two related proteins.

The three primary antibody positive clones, PAI17, PAI20, and PAI9, all overlap at the DNA level (Fig. 2). The fusion

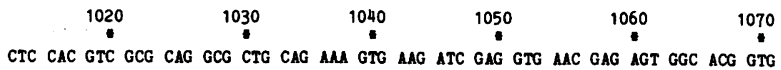
CTC CAC GTC GCG CAG GCG CTG CAG AM GTG AAG ATC GAG GTG AAC GAG AGT GGC ACG GTG
Leu His Val Ala Gin Ala Leu Gin Lys Val Lys Ile Glu Val Asn Glu Ser Gly Far Val 357 1080
GCC TCC TCA TCC ACA GCT GTC ATA GTC TCA GCC OCC ATC GCC
N1a Ser Ser Ser Thr Mla Val Ile Val Ser Mla Arg Met Mla

AG GAG ATC ATC ATG GAC AGA CCC TTC CTC TTT GTG GTC CGG CAC AMC CCC ACA
CCC GAG GAG ATC ATC ATG GAC AGA CCC TTC CTC TTT GTG GTC CGG CAC AAC CCC ACA
Pro Glu Glu Ile Ile Met Asp Arg Pro Phe Leu Phe Val Val Arg His Asn Pro Thr

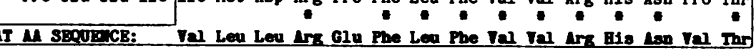
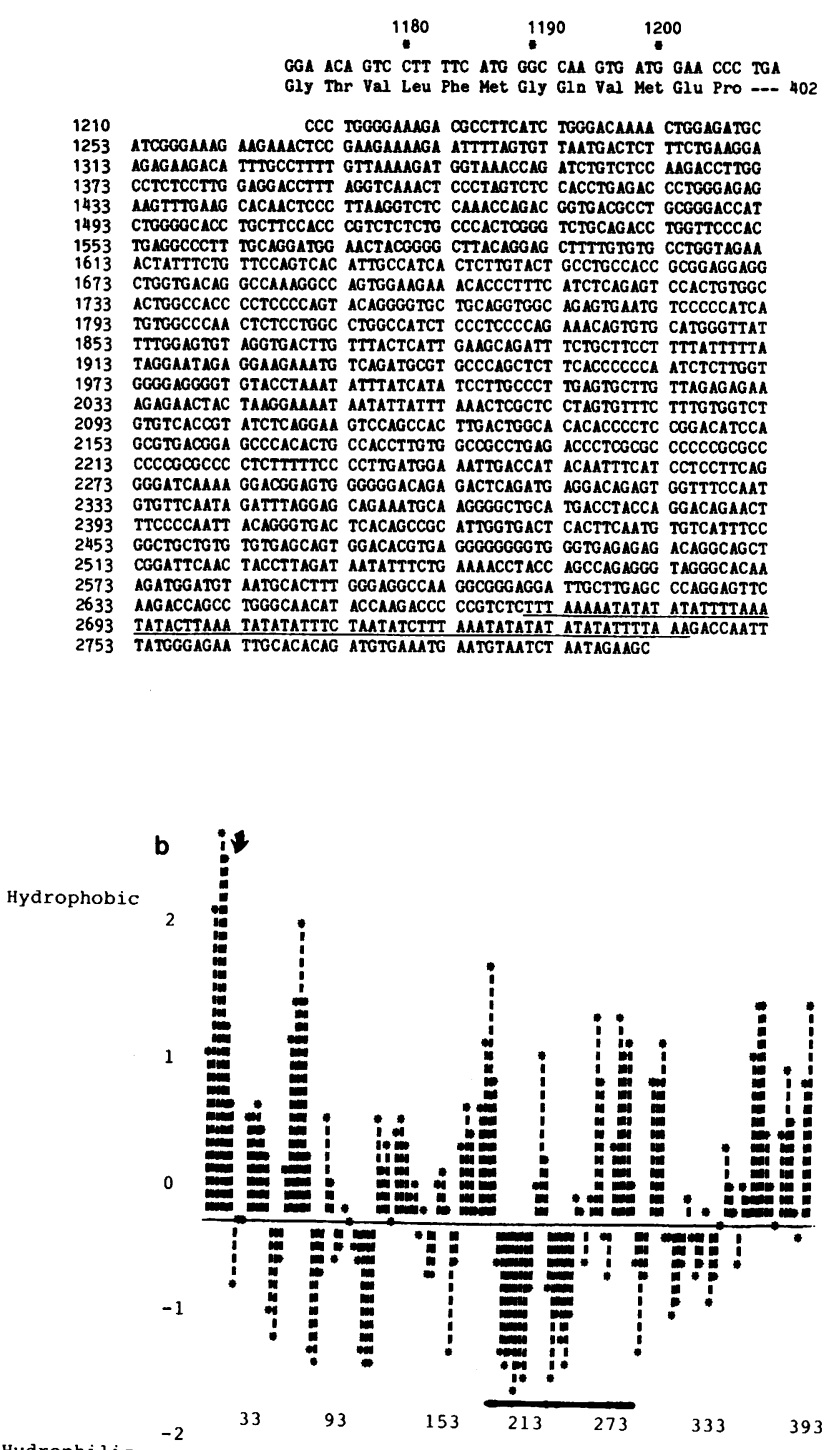

Hydrophilic

codon following amino acid residue $\mathbf{4 0 2}$ is indicated by three dashes. The 75-bp AT-rich sequence in the $3^{\prime}$ untranslated region is underlined. (b) Hydropathy plot. This was determined for the predicted fulllength amino acid sequence of PAI-1, using the Pustell sequence analysis program (33). Relative hydrophobicity is plotted along the $\mathrm{Y}$ axis with amino acid residue number along the $X$ axis. The hydrophobic leader sequence is marked with an arrow. The dark line indicates the position of the overlapping coding sequence present in clones PAI9, PAI17, and PAI20.

proteins encoded by all three clones also react with monoclonal $\mathrm{Ab} \mathrm{IA} \mathrm{A}_{5}$. The $5^{\prime}$ ends of the three sequences begin within five codons of each other and the region of overlap encodes amino acid residues 204-280, thus localizing the epitope for this monoclonal $\mathrm{Ab}$. This region is seen to correspond to the most hydrophilic portion of the molecule (Fig. $5 B$ ), and may represent 
Table I. Amino Acid Homology Comparisons between Selected SERPINs

\begin{tabular}{lllllll}
\hline & Angiotensinogen & $\alpha$-1-Antitrypsin & Ovalbumin & Antithrombin III & $\alpha$-1-Antichymotrypsin & PAI-1 \\
\hline & & $\%$ & $\%$ & $\%$ & $\%$ & $\%$ \\
Angiotensinogen & - & $24.6(400)$ & $21.4(359)$ & $22.2(373)$ & $22.8(377)$ & $21.8(362)$ \\
$\alpha$-1-Antitrypsin & - & - & $30.4(595)$ & $29.3(590)$ & $38.9(841)$ & $29.9(606)$ \\
Ovalbumin & - & - & - & $31.2(615)$ & $29.7(554)$ & $27.9(544)$ \\
Antithrombin III & - & - & - & - & $31.2(587)$ & $28.9(653)$ \\
$\alpha$-1-Antichymotrypsin & - & - & - & - & & $29.4(542)$ \\
\end{tabular}

Amino acid homology comparisons are shown between several members of the SERPIN gene family, including PAI-1. Calculations were performed with the DNASTAR amino acid alignment program using the Needleman-Wunsch algorithm (34). The percentages refer to the percentage identity in the region of amino acid overlap. The numbers in parentheses are the optimized score calculated by the computer program, with higher numbers indicating a greater level of statistical significance.

a prominently exposed portion of the protein. Such a dominant epitope could explain why all three clones detected with our polyclonal antiserum map to this same region.

The larger PAI-1 mRNA species (Fig. $3 A$ ) is $\sim 3$ kb long. The cDNA sequence Fig. $5 A$ shows contains 2,869 nucleotides and thus should include nearly the complete PAI- 1 sequence. The poly-A tail found at the $3^{\prime}$ terminus of most eukaryotic mRNAs is missing from our sequence as well as the highly conserved poly-A addition signal, AAUAAA, which precedes the tail by $\sim 15$ nucleotides; (these are also not present at the 3 ' end of the 2-kb cDNA clone, PAIB6). This probably represents an artifact inherent in our cDNA synthesis. Multiple phage clones have been examined from this library, both for PAI-1 as well as for a number of other endothelial cell mRNAs. Most of these clones are missing a poly-A-tract and generally have lost $\sim 100$ 200 nucleotides from the $3^{\prime}$ end $(24,25$, and D. Ginsburg, unpublished observation). Considering the probable loss of $\sim 150$ nucleotides from the $3^{\prime}$ end of the sequence, this should account for the entire length of the PAI-1 mRNA.

We cannot exclude the presence of a small amount of additional sequence at the $5^{\prime}$ end. The first ATG codon appears at nucleotide 69 of our sequence. Because this putative initiator

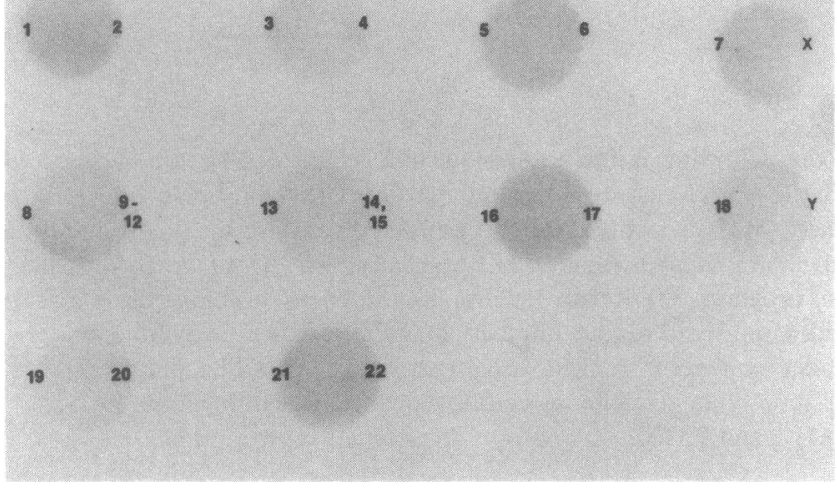

Figure 6. Spot-blot hybridization of radiolabeled gene probe. 1225 $\mathrm{mm}$ circular nitrocellulose filters with two chromosome spots each are displayed with the numbers on the edge of each filter adjacent to each sorted chromosome spot. Chromosome 7 hybridizes more intensely, mapping the PAI-1 gene to that chromosome. The lighter gray background is nonspecific hybridization to the filters. codon is not preceded by an in-frame stop codon, we cannot rule out the existence of another potential initiator codon further upstream. However, the 68-nucleotide-long 5 untranslated region found in this sequence is an average length for eukaryotic mRNA, and the sequence immediately preceding the proposed initiator codon is consistent with the consensus sequence proposed by Kozak (45). A second ATG present only two codons downstream would be expected to function poorly as an initiator codon, with a pyrimidine present at position $-3(45)$. The candidate initiator codon is followed by a typical hydrophobic leader sequence containing a core of 13 hydrophobic residues (codon 6-18) with a predicted cleavage site after the alanine at codon 23 (46). This sequence encodes a preprotein of 402 amino acids, with the mature protein predicted to be 379 amino acids long, with an $M_{\mathrm{r}}$ of $42.7 \mathrm{kD}$. This sequence is remarkable for the presence of only a single cysteine which is located in the leader sequence. Rat PAI-1 is also low in cysteine content with amino acid composition showing only one cysteine residue per molecule (Zeheb, R., and T. Gelehrter, unpublished data). PAI-1 is known to be glycosylated $(3,8)$ and the sequence predicts three potential $\mathrm{N}$-glycosylation sites (with the canonical sequence Asn-X-Ser/ Thr where $X$ is not Pro) (40). Interestingly, the presence of a Val in rat PAI-1, in place of Pro389 in the human (the single difference in a 10 amino acid segment), creates an additional potential $\mathrm{N}$-glycosylation acceptor site in the rat protein (Fig. $5 \mathrm{~A}$ ).

Northern blot analysis of endothelial cell mRNA reveals two PAI- 1 mRNA species, 3 and $2 \mathrm{~kb}$ long, respectively. The difference between these two species resides entirely in the $3^{\prime}$ untranslated region where the larger mRNA contains an extra $1 \mathrm{~kb}$. The molecular mechanism for this is not clear from our sequence though it may represent alternative polyadenylation. No consensus poly-A signal (AATAAA) is found in the sequence near the end of the 2-kb mRNA (approximately position 2000). Possibly, TTTAAA (position 2060), AAATAA (position 2049), or CCTAAA (position 1986), could function as a weak poly-A signal. If this is the case, alternative processing at a more favorable downstream polyadenylation signal could account for an abundant longer message. Alternative splicing could also account for the finding of two mRNA species. The existence of alternatively processed mRNAs could provide a mechanism for posttranscriptional regulation of PAI-1 expression. To date, we have not observed any difference in the ratio of the $3 \mathrm{~kb}$ to $2 \mathrm{~kb}$ PAI-1 mRNAs in endothelial cells grown under varying conditions (Konkle, B., and D. Ginsburg, unpublished data). 
The $3^{\prime}$ end of the larger message (residues 2,670-2,744) contains an unusual sequence that is adenine-thymine (AT)-rich and contains a 75-bp imperfect palindrome. Within this are three smaller palindromes of 16,12 , and $18 \mathrm{bp}$ long. This region is immediately preceded by a partial Alu repetitive element (nucleotides 2560-2677) (47). This AT-rich sequence might play an important role in the regulation of PAI-1 gene expression by a number of possible mechanisms. The sequence can assume a number of complex RNA secondary structures involving hairpin loop formation. The high degree of symmetry and predicted low melting temperature might also signify a region of protein-nucleic acid interaction, either at the DNA or RNA level. Meijlink et al. (48), have recently reported a 67-nucleotide-long AT-rich sequence located 189 bp upstream of the poly-A addition site in the normal c-fos mRNA. Removal of this sequence was sufficient to convert this normal cellular homologue to a transforming gene. Recently Caput et al. (49), have noted a repetitive AT-rich $3^{\prime}$ untranslated sequence shared between mRNAs for a number of different inflammatory mediators and postulate that this sequence may have a common regulatory role.

The isolation of PAI-1 cDNA sequences should facilitate the future study of the regulation of PAI-1 gene expression at the molecular level. Determination of PAI-1 genomic structure should also be of interest. The gene family of serine proteases provides an excellent model for the concept of "exon shuffling". Intron-exon boundaries are highly conserved between different members of the family and sharply delineate specific functional domains $(41,44)$. In contrast, the distribution of introns in the serine protease inhibitor gene family is difficult to fit into a simple model. The number of introns varies widely, and the precise location of these introns is not highly conserved $(43,50)$. The number and placement of introns for the two forms of PAI, PAI-1 and PAI-2, may shed further light on the process of SERPIN intron evolution. The availability of cDNA and genomic PAI- 1 sequences should also prove useful for the evaluation of possible genetic defects in PAI-1 as major risk factors for thromboembolic diseases in humans.

\section{Acknowledgments}

We thank Julia Richards for help with the homology analysis, Francis Collins for thoughtful review of the manuscript, Evan Sadler for sharing sequence data before publication, Robert Flandenmeyer for assistance with the sorted chromosome hybridization studies, and Anne Brancheau for help in preparing the manuscript.

Dr. Ginsburg is a Howard Hughes Medical Institute Investigator. This work was supported in part by funds from National Institutes of Health grant CA-22729 to Dr. Gelehrter and from Institutional Research grant No. IN-40Z to the University of Michigan from the American Cancer Society to Dr. Zeheb. Dr. Zeheb is a recipient of a National Research Service Award (CA-07783).

\section{References}

1. Erickson, L. A., R. R. Schleef, T. Ny, and D. J. Loskutoff. 1985. The fibrinolytic system of the vascular wall. Clin. Haematol. 14:513530.

2. Erickson, L. A., M. H. Ginsberg, and D. J. Loskutoff. 1984. Detection and partial characterization of an inhibitor of plasminogen activator in human platelets. J. Clin. Invest. 74:1465-1472.

3. Erickson, L. A., C. M. Hekman, and D. J. Loskutoff. 1985. The primary plasminogen-activator inhibitors in endothelial cells, platelets, serum, and plasma are immunologically related. Proc. Natl. Acad. Sci. USA. 82:8710-8714.
4. Sprengers, E. D., H. M. G. Princen, T. Kooistra, and V. M. W. Van Hinsbergh. 1985. Inhibition of plasminogen activators by conditioned medium of human hepatocytes and hepatoma cell line Hep G2. J. Lab. Clin. Med. 105:751-758.

5. van Mourik, J. A., D. A. Lawrence, and D. J. Loskutoff. 1984. Purification of an inhibitor of plasminogen activator (antiactivator) synthesized by endothelial cells. J. Biol. Chem. 259:14914-14921.

6. Kruithof, E. K. O., C. Tran-Thang, A. Ransijn, and F. Bachmann. 1984. Demonstration of a fast-acting inhibitor of plasminogen activators in human plasma. Blood. 64:907-913.

7. Kluft, C., A. F. H. Jie, E. D. Sprengers, and J. H. Verheijen. 1985. Identification of a reversible inhibitor of plasminogen activators in blood plasma. FEBS (Fed. Eur. Biochem. Soc.) Lett. 190:315-318.

8. Andreasen, P. A., L. S. Nielsen, P. Kristensen, J. Grandahl-Hansen, L. Skriver, and K. Dano. 1986. Plasminogen activator inhibitor from human fibrosarcoma cells binds urokinase-type plasminogen activator, but not its proenzyme. 1986. J. Biol. Chem. 261:7644-7651.

9. Coleman, P. L., P. D. Patel, B. J. Cwikel, U. M. Rafferty, R. Sznycer-Laszuk, and T. D. Gelehrter. 1986. Characterization of the dexamethasone-induced inhibitor of plasminogen activator in HTC hepatoma cells. J. Biol. Chem. 261:4352-4357.

10. Colucci, M., J. A. Paramo, and D. Collen. 1985. Generation in plasma of a fast-acting inhibitor of plasminogen activator in response to endotoxin stimulation. J. Clin. Invest. 75:818-824.

11. Gelehrter, T. D., and R. Sznycer-Laszuk. 1986. Thrombin induction of plasminogen activator-inhibitor in cultured human endothelial cells. J. Clin. Invest. 77:165-169.

12. Emeis, J. J., and T. Kooistra. 1986. Interleukin 1 and lipopolysaccharide induce an inhibitor of tissue-type plasminogen activator in vivo and in cultured endothelial cells. J. Exp. Med. 163:1260-1266.

13. van Hinsbergh, V. W. M., R. M. Bentina, A. van Wijngaarden, N. H. van Tilburg, J. J. Emeis, and F. Haverkate. 1985. Activated protein $\mathrm{C}$ decreases plasminogen activator-inhibitor activity in endothelial cellconditioned medium. Blood. 65:444-451.

14. Gelehrter, T. D., P. A. Barouski-Miller, P. L. Coleman, and B. J. Cwikel. 1983. Hormonal regulation of plasminogen activator in rat hepatoma cells. Mol. Cell. Biochem. 53/54:11-21.

15. Cwikel, B. J., P. A. Barouski-Miller, P. L. Coleman, and T. D. Gelehrter. 1984. Dexamethasone induction of an inhibitor of plasminogen activator in HTC hepatoma cells. J. Biol. Chem. 259:6847-6851.

16. Andreasen, P. A., T. H. Christensen, J.-Y. Huang, L. S. Nielsen, E. L. Wilson, and K. Dano. 1986. Hormonal regulation of extracellular plasminogen activators and $M_{r} \sim 54,000$ plasminogen activator inhibitor in human neoplastic cell lines studied with monoclonal antibodies. Mol. Cell. Endocr. 45:137-147.

17. Nilsson, I. M., and L. Tengborn. 1984. A family with thrombosis associated with high level of tissue plasminogen activator inhibitor. Haemostasis. 14:24.

18. Hamsten, A., B. Wiman, U. de Faire, and M. Blomback. 1985. Increased plasma levels of a rapid inhibitor of tissue plasminogen activator in young survivors of myocardial infarction. N. Engl. J. Med. 313:15571563.

19. Wiman, B., B. Ljungberg, J. Chmielewska, G. Urden, M. Blomback, and H. Johnsson. 1985. The role of the fibrinolytic system in deep vein thrombosis. J. Lab. Clin. Med. 105:265-270.

20. Astedt, B., I. Lecander, T. Brodin, A. Lundblad, and K. Low. 1985. Purification of a specific placental plasminogen activator inhibitor by monoclonal antibody and its complex formation with plasminogen activator. Thromb. Haemostasis. 53(1):122-125.

21. Vassali, J. D., J. M. Cayer, A. Wohlwend, and D. Belin. 1984. Concomitant secretion of prourokinase and of plasminogen activatorspecific inhibitor by cultured human monocyte-macrophages. J. Exp. Med. 159:1653-1668.

22. Nielsen, L. S., P. A. Andreasen, J. Grandahl-Hansen, J. Y. Juang, P. Kristensen, and K. Dano. 1986. Monoclonal antibodies to human 54,000 molecular weight plasminogen activator inhibitor from fibrosarcoma cells: inhibitor neutralization and one-step affinity purification. Thromb. Haemostasis. 55:206-212.

23. Dale, R. M. K., B. A. McClure, and J. P. Houchins. 1985. A 
rapid single-stranded cloning strategy for producing a sequential series of overlapping clones for use in DNA sequencing. Plasmid. 13:31-40.

24. Ginsburg, D., R. I. Handin, D. T. Bonthron, T. A. Donlon, G. A. P. Bruns, S. A. Latt, and S. H. Orkin. 1985. Human von Willebrand Factor ( $\mathrm{vWF}$ ): isolation of complementary DNA (cDNA) clones and chromosomal localization. Science (Wash. DC). 228:1401-1406.

25. Collins, T., D. Ginsburg, J. M. Boss, S. H. Orkin, and J. S. Pober. 1985. Cultured human endothelial cells express platelet-derived growth factor chain 2: cDNA cloning and structural analysis. Nature (Lond.). 316:748-750.

26. Young, R. A., and R. W. Davis. 1985. Immunoscreening lambda gt11 recombinant DNA expression libraries. In Genetic Engineering. Vol. 7. J. Setlow and A. Hollaender, editors. Plenum Publishing Corp., New York. 29-41.

27. Johnson, D. A., J. W. Gautsch, J. R. Sportsman, and J. H. Elder. 1984. Improved techniques utilizing nonfat dry milk for analysis of proteins and nucleic acids transferred to nitrocellulose. Gene Anal. Techn. $1: 3-8$.

28. Hawkes, R. 1982. Identification of concanavilin A binding proteins after sodium dodecyl sulfate gel electrophoresis and protein blotting. Anal. Biochem. 123:143-146.

29. Maniatis, T., E. F. Fritsch, and J. Sambrook. 1982. Molecular Cloning: A Laboratory Manual. Cold Spring Harbor Laboratory, Cold Spring Harbor, New York. 545 pp.

30. Feinberg, A. P., and B. Vogelstein. 1983. A technique for radiolabeling DNA restriction endonuclease fragments to high specific activity. Anal. Biochem. 132:136.

31. Sanger, F., S. Nicklen, and A. R. Coulson. 1977. DNA sequencing with chain-terminating inhibitors. Proc. Natl. Acad. Sci. USA. 74:5463.

32. Messing, J. 1983. New M13 vectors for cloning. Methods Enzymol. 101:20.

33. Pustell, J., and F. C. Kafatos. 1986. A convenient and adaptable microcomputer environment for DNA and protein sequence manipulation and analysis. Nucleic Acids Res. 14:479-488.

34. Doggett, P. E., and F. R. Blattner. 1986. Personal access to sequence databases on personal computer. Nucleic Acids Res. 14:611-619.

35. Burnette, W. N. 1981. Western blotting: electrophoretic transfer of proteins from sodium dodecyl sulfate- polyacrylamide gels to unmodified nitrocellulose and radiographic detection with antibody and radioiodinated protein A. Anal. Biochem. 112:195-203.

36. Koide, T., and T. Ikenaka. 1973. Studies on soybean trypsin inhibitors. I. Fragmentation of soybean trypsin inhibitor by limited proteolysis and by chemical cleavage. Eur. J. Biochem. 32:401-407.
37. Tarr, G. E. 1986. Manual edman sequencing system. In Microcharacterization of Polypeptides: A Practical Manual. J. E. Shively, editor. Humana Press, Clifton, New Jersey, In press.

38. Lebo, R. V., F. Gorin, R. J. Fletterick, F. T. Kao, M. C. Cheung, B. D. Bruce, and Y. W. Kan. 1984. High-resolution chromosome sorting and DNA spot-blot analysis assign McArdle's syndrome to chromosome 11. Science (Wash. DC). 225:57-59.

39. Lebo, R. V., B. D. Bruce, P. F. Dazin, and D. Payan. 1987. Design and application of a versatile triple laser cell and chromosome sorter. Cytometry. In press.

40. Bause, E. 1983. Structural requirements of $\mathrm{N}$-glycosylation of proteins. Studies with proline peptides as conformational probes. Biochem. J. 209:331-336.

41. Patthy, L. 1985. Evolution of the proteases of blood-coagulation and fibrinolysis by assembly from modules. Cell. 41:657-663.

42. Doolittle, R. F. 1983. Angiotensinogen is related to the antitrypsinantithrombin-ovalbumin family. Science (Wash. DC). 222:417-419.

43. Carrell, R. W., and D. R. Boswell. 1986. SERPINS: the superfamily of plasma serine proteinase inhibitors. In Proteinase Inhibitors. A. Barrett, and G. Salvesen, editors. Elsevier, Amsterdam. In press.

44. Verstraete, M., and D. Collen. 1986. Thrombolytic therapy in the eighties. Blood. 67:1529-1541.

45. Kozak, M. 1984. Compilation and analysis of sequences upstream from the translational site in eukaryotic mRNAs. Nucleic Acids Res. 12: 857-872.

46. Perlman, D., and H. O. Halvorson. 1983. A putative signal peptidase recognition site and sequence in eukaryotic and prokaryotic signal peptides. J. Mol. Biol. 167:391-409.

47. Deininger, P. L., J. J. Douglas, C. M. Rubin, T. Friedmann, and C. W. Schmid. 1981. Base sequence studies of 300 nucleotide renatured repeated human DNA clones. J. Mol. Biol. 151:17-33.

48. Meijlink, F., T. Curran, A. D. Miller, and I. M. Verma. 1985. Removal of a 67-base-pair sequence in the noncoding region of protooncogene fos converts it to a transforming gene. Proc. Natl. Acad. Sci. USA. 82:4987-4991.

49. Caput, D., B. Beutler, K. Hartog, R. Thayer, S. Brown-Shimer, and A. Cerami. 1986. Identification of a common nucleotide sequence in the 3'-untranslated region of mRNA molecules specifying inflammatory mediators. Proc. Natl. Acad. Sci. USA. 83:1670-1674.

50. Prochownik, E. V., S. C. Bock, and S. H. Orkin. 1985. Intron structure of the human antithrombin III gene differs from that of other members of the serine protease inhibitor superfamily. J. Biol. Chem. 260:9608-9612. 